O amor é definido por Freud como uma moção comum a muitas situaçōes dentre as quais a relação amorosa e o amor de transferência. O autor explora as diferentes facetas da relação amorosa, chamada enamoramento, por motivos clínicos precisos, e particularmente em função da transformação do amor em ódio, que em francês se entende no significante enamoração. As correspondências e também as distinçōes com o amor de transferência são precisas, tanto nos tratamentos de adolescentes quanto nos de adultos. Amor; enamoramento; transferência; ódio; paixão amorosa

"ENAMORATION" AND LOVE IRANSFERANCE

Freud describes love as commun with many situations such as being in love with someone and love transferance. The author explores the differents forms of the love affairs wich he calls "énamoration" for precises clinical reasons, particularely in relation with the reversil of love into hate, wich in french only can be heard in the signiticier "enamoration". The correspondances and the differences with love transferance are precised, both in analysis of adolescents and adults.

Love; being in love; "enamoration"; tranferance; hate; passion of love

\section{O ENAMORAMENTO E O AMOR DE TRANSFERÊNCIA}

\author{
Didier Lauru
}

Tradução: Inesita Machado

${ }^{1}$ reud, ao longo de sua obra, sempre falou de amor. Ele se interessou pelo tema a partir de múltiplos ângulos, dos quais dois emergem particularmente:

- o amor propriamente dito, em todos os desenvolvimentos sobre a psicopatologia e a vida amorosa (Freud, 1977);

- o amor de transferência na clínica analítica. Esse enigma esperava por Freud na virada da descoberta do inconsciente, a saber, a natureza dos sentimentos transferenciais positivos (pelo menos no início) dos pacientes sobre a pessoa do analista. Foi assim que, em 1907 - portanto, bem cedo em sua obra -, ele declarou numa das "noites de quartafeira": "Obrigamos o paciente a renunciar a suas resistências por amor a nós. Nossos tratamentos são tratamentos pelo amor”.

Esse modo de conceber o amor e também o amor de transferência é extremamente impreciso. $\mathrm{O}$ prosseguimento de seu deciframento dos arcanos do amor o conduzirá a distinguir e a comparar nitida- 
mente os respectivos lugares do amor propriamente dito e do amor de transferência.

Ele irá evoluir consideravelmente em suas perspectivas e, principalmente, em sua teoria das pulsões. Ressaltamos, assim, que o amor está na confluência de vários conceitos analíticos, que devem ser usados para dele nos darmos conta. Os principais são: sexualidade ou libido, pulsão, identificação - para citar apenas os principais - com recalque, fantasma, inconsciente, transferência, etc. A teoria freudiana do amor condensa de fato uma parte importante do edifício teórico-analítico.

Tomados num sentido amplo, os termos "amor" e "sexualidade" poderiam ser equivalentes, ambos encerrados numa atividade sexual genital, mas também no fator psíquico da vida sexual.

Historicamente, foi em 1920 que Freud modificou sua teoria das pulsões e, para aquilo que nos interessa, vem assimilar as pulsões sexuais com o Eros dos poetas, enquanto "mantém a coesão em todas as coisas".

\section{O AMOR SEGUNDO FREUD}

Freud efetua igualmente um salto epistemológico importante quando nāo segue os filósofos gregos, que faziam a distinção entre quatro tipos de Philia (afeição, amor):

- Physikè (entre os seres de uma mesma família);

- Xeniquè (entre os hóspedes);

- Hetaïrikè (entre amigos);

- Erotikè (entre pessoas do mesmo sexo ou de sexos diferentes).

Veremos de que modo Freud engloba todos esses diferentes registros para fazer deles um único amor. Em 1921, em Psicologia das massas e análise do eu (1983), Freud define o amor nesta longa citação, que requer um pouco de concentração para que se perceba onde ele quer chegar. Mas essa visão sintética é de notável clareza:

$O$ núcleo daquilo que chamamos amor é formado naturalmente por aquilo que é comumente conhecido como amor e que é cantado pelos poetas, isto é, o amor sexual, cujo termo é constituído pela união sexual. Mas não separamos todas as outras variedades de amor, tais como o amor por si mesmo, o amor que sentimos por pais e filhos, a amizade, o amor dos homens em geral, não mais do que não separamos o apego a objetos concretos e a idéias abstratas. Para justificar a extensão que damos ao termo "amor", podemos citar resultados revelados pela pesquisa psicanalítica, ou 
seja, que todas essas variedades de amor são expressões de um único e mesmo conjunto de tendências, as quais, em alguns casos, convidam a união sexual, enquanto outras desviam desse objetivo ou impedem a sua realização, conservando traços característicos de sua natureza de modo a que não nos enganemos sobre a sua identidade [...]. Pensamos que, dando à palavra uma tal multiplicidade de significações, estariamos apenas colocando esta sintese na base de nossas consideraçôes.

Essa magistral citação requer alguns comentários. No entanto, podemos apenas ter admiração diante da concisão do verbo freudiano e de sua visão globalizante do amor. Tendo partido do amor comum, ele faz um paralelo com outros tipos de amor - filial, parental, de amizade e a estima que têm as pessoas entre si de um modo global. Isso pode parecer evidente numa primeira abordagem; entretanto, seria conveniente identificar os traços específicos $e$ as distinções.

Parece-me importante, entretanto, rever com precisão o que Freud já queria diferenciar: ... todas essas variedades de amor são expressóes de um único e mesmo conjunto de tendências, as quais, em alguns casos, convidam a união sexual, enquanto outras desviam desse objetivo ou impedem a sua realização. Extraio aqui dois pontos que vou desenvolver:

- as diferentes tendências que convidam à união sexual e as que dela desviam ou impedem sua realização;

- o amor propriamente dito, em que ele revela assim sua dupla face, sem nomeá-la aqui - ele o fará mais tarde - ou seja, que o amor tem um reverso: o ódio. Esse reverso é contra tudo, contra o próprio amor; é, apesar de tudo, o ódio. Voltaremos a isso, pois é o que nos introduzirá ao enamoramento. É também a antecipação daquilo que ele ainda não diz, ou seja, a transposição do amor de transferência com seus dois pólos opostos retomados em numerosas ocorrências: a transferência como motor da cura, no sentido do amor de transferência, mas também a transferência como resistencia ao trabalho do inconsciente e da cura.

\section{O BANQUETE DE PLATÃO}

Proponho arbitrariamente começar pela exposição dos pontos de vista em torno da relação amorosa e em seguida aprofundar a transferência do amor, em suas disparidades subjetivas, mas também em seus arcanos do quotidiano da prática, que esclarece a teoria analítica de um dia específico e que é de rara precisão. A clínica nos será de 
grande auxílio para ilustrar essa teoria pertinente. Vocês vêem que temos trabalho em perspectiva! Farei aqui apenas um esboço.

$\mathrm{Na}$ realidade, essa escolha não é tão arbitrária quanto parece, pois convém referir-se ao ponto em que a realidade faz corpo com a experiência, no seio do estado amoroso, e, em seguida, passar à subjetividade da transferência, em suas modalidades amorosas, bem como odiosas.

Em Três ensaios sobre a teoria da sexualidade, Freud (1982) diferencia claramente dois registros: o do amor dito normal (Liebe), por oposição à paixão amorosa que encontramos regularmente no enamoramento (Verliebeith).

Para o amor normal, Freud se refere ao mito enunciado por Aristófanes no Banquete de Platão. Lacan retomará uma leitura próxima ao texto para construir uma teoria da transferência coerente com suas elaborações teóricas, das quais ele destacará o lugar do analista como Sujeito suposto saber.

Freud é bastante inovador em sua experiência e em seu modo de conceber o amor, reelaborado na medida da experiência analítica, ou seja, o amor verdadeiro é um amor que não é real. É esta a revolução freudiana em toda a sua subversão. Lacan saberá retomar o vivo deste ângulo subversivo e radicalmente outro. É também todo o caminho percorrido entre a visão platônica do mito do amor e a outra vertente do amor como engano. É, no mito platônico, toda a distância entre a possível complementaridade no outro sexo e a experiência analítica que mostra a impossível complementaridade sexual, mas, também, a busca pelo sujeito não de um complemento sexual, mas de outra coisa. Esta outra coisa será de fato desenvolvida mais tarde por Lacan numa versão em que a imagem do outro será visada em seu aspecto enganador da imagem de amor.

Apresento brevemente a passagem do Banquete de Platão onde está em questão esse mito fundador do imaginário do amor em nossas sociedades ocidentais pós-modernas. A espécie humana dividia-se então em três gêneros: o masculino, o feminino e o andrógino. Este último possuía as características dos dois sexos, isto é: quatro braços, quatro pernas, dois rostos opostos numa só cabeça e dois sexos. Com força e vigor estupendos, desafiaram os deuses tentando escalar o céu. Zeus decidiu então parti-los em dois. Com os corpos assim desdobrados, não pensavam em outra coisa: encontrar-se finalmente reunidos. Como não podiam se reproduzir, Zeus decidiu dar-lhes um sexo para que pudessem gerar.

Assim, no amor ao semelhante, trata-se de encontrar nossa "metade" e de reencontrar essa unidade primeira e para sempre perdida. 
Esse aspecto da nostalgia de um amor antigo e de uma unidade para sempre desaparecida responde a certos aspectos da relação de amor. Freud se refere com freqüência à teoria platônica do amor, da qual identifica a proximidade com aquilo que ele qualifica de "sexualidade". Ele observou que esta devia ser diferenciada da sexualidade genital. E havia indicado, muito antes, na Tramdeutung, que seria preciso utilizar a palavra "sexual" no sentido em que a psicanálise a emprega agora no sentido de Eros.

Lacan fará uma releitura precisa que demonstra o limite do uso desse mito, que não considera a dimensão do inconsciente.

\section{O ENAMORAMENTO}

Qualifico assim a relação amorosa atribuindo-lhe uma conotação que vem do amor, mas não somente. O sujeito é levado progressivamente ao ponto em que o ódio é parte integrante da relação amorosa, e é por isso que proponho o significante "enamoramento", termo da língua francesa pouco usado nos dias de hoje. Lacan forjou o neologismo "amoródio"; seu ponto de insistência dizia respeito então ao significante ouvido, o ódio, compreendido como implícito no amor.

Freud ressaltou muito cedo aquilo que a psicanálise concebia para o termo "sexualidade", que "comporta um sentido muito mais amplo. Este se distancia do sentido popular e essa extensão se justifica pelo sentido genético. Consideramos como pertencendo ao domínio da sexualidade todas as manifestações de sentimentos ternos decorrentes da fonte das emoções sexuais primitivas, até mesmo quando essas emoções foram desviadas de seu objetivo sexual originário ou que um outro objetivo tenha vindo substituir o primeiro. É por isso que preferimos falar em psicossexualidade, ressaltando assim que não se deve nem negligenciar nem subestimar o fator psíquico".

Este termo "psicossexualidade" não teve um futuro florescente. Freud irá redefini-lo mais tarde e englobá-lo no termo "sexualidade". Depois, emerge o conceito de libido e finalmente a palavra Eros para significar aquilo que ele entende por sexualidade. Essa evolução é paralela à evolução de sua teoria das pulsões.

De fato, a palavra "sexualidade" reagrupa, como vimos, um sentido extenso do verbo alemão (lieben) que significa "amar". Mas uma falta de satisfação psíquica pode existir, ali mesmo onde as relações sexuais normais existem. Clinicamente, podemos observar que aspirações sexuais insatisfeitas com freqüência não chegam ao coito ou outros atos sexuais. Mas iremos desenvolver esse ponto preciso mais adiante.

\section{O REAL DA RELAÇÃO AMOROSA}

O enamoramento é um modo de acesso privilegiado ao real do amor, que é também uma experiência 


\section{Fundamentos}

comumente partilhada pelo maior número de pessoas.

Freud insiste sobre o caráter passional (Liedenschaft) e a vertente anormal desse tipo de amor, que ele coloca mais do lado patológico do que do normal. É a partir daí que se torna possível sustentar a idéia de uma loucura transitória que seria o enamoramento.

Vejamos, em detalhe, os argumentos elaborados por Freud (1977) em Observações sobre o amor de transferência.

O enamoramento comporta um traço específico que é, para permanecer em termos freudianos, uma superestimação sexual do objeto, secundária a uma idealização. Essa idealização se faz por uma escolha de objeto, cuja natureza narcísica não escapará a ninguém.

Entretanto, "o objeto é tratado como o próprio eu", isto é, o eu se comporta como se quisesse atrair a atenção sobre si mesmo e ceder lugar a um outro, pois "o objeto, por assim dizer, absorveu o eu" e ocupou o lugar de ideal de eu.

Quando Freud tenta demonstrar a qualidade particular do amor de transferência e que ele não faz objeção a qualificá-lo de amor verdadeiro, ele vai fazer algumas distinções. Para Freud, não existe amor que não tenha seu protótipo na infância. Esta visão me parece correta numa primeira abordagem e ao mesmo tempo limitante, restritiva. É como se ele não considerasse o trabalho metapsicológico da adolescência. Freud insiste, especificando que é o fator infantil que dá ao amor "seu caráter compulsivo e frisando 
o patológico". Ele diferencia também graus de alienação no amor, precisando que aquele que sobrevém no quadro da transferência é "um grau menos livre" do que aquele que encontramos na vida comum. E isso não nos assegura de nada!

Mais adiante ele se aprofunda quando propõe que todo estado amoroso "lembra mais fenômenos anormais do que normais". No entanto, dois elementos estão ligados à situação analítica: a própria situação analítica a resistência. O terceiro elemento é o fato de que o amor se revela menos racional, menos preocupado com as conseqüências e mais cego na apreciação dos re-amado, mas Freud precisa "que esperamos um amor normal". É assim que se deve ouvir Freud nos falar de uma loucura amorosa, pois ela tende em direção ao não-racional e que ela não considera as realidades. Tratar-se-ia aí de um adulto falando dos amores tumultuosos da juventude?

Ele acrescenta, efetivamente, que são precisamente essas características anormais que formam o essencial do estado amoroso.

A exigência do analista impõe o questionamento da problemática ligada ao amor de transferência, e será conveniente fazer distinções precisas entre amor e amor de transferência. As sociedades pós-modernas, tão particulares, oscilam entre reações conservadoras e limitantes da sexualidade e uma apetência ao liberalismo em matéria de sexualidade, como ilustrado nas mídias em torno do recente caso Cohn-Bendit.

Isto ilustra a atualidade do malestar na civilização e a alternância entre fases de liberação dos costumes e de retorno a uma excessiva moralidade em matéria de relações amorosas e de sexualidade. O que Freud já havia identificado e que the havia possibilitado uma análise penetrante da situação, bem como de se opor vivamente às derivações de alguns de seus discípulos, como Jung, Adler ou Reich.

Mas o analista, qualquer que seja a moral sexual civilizada que regule o sócius, deverá permanecer em posições éticas incontornáveis e nãomovíveis.

As diferentes distinções entre o amor e o amor de transferência não devem permitir que se esqueça o essencial: o amor de transferência, ainda que sempre presente, pronto para encontrar um objeto sobre o qual se dirigir, é artificialmente criado pela situação analítica. Assim, a acura, lugar de palavra, lugar em que as palavras podem se ouvir alhures, e estão no fundo de significantes que apenas demandam serem liberados de suas significações bloqueadas. A cura é, portanto, um lugar em que a palavra prima sobre o ato e em que, precisamente, o estabelecimento da transferência vai de encontro à barreira ética intransponível, tão bem descrita por Freud em suas observações sobre o amor de transferência.

A atual multiplicação de todo tipo de psicoterapias, em que algumas utilizam o discurso psicanalítico para tentar justificar práticas inqualificáveis, não vem absolutamente da cura psicanalítica. Mas é preciso "varrer a própria porta", pois situações trazidas por alguns analisandos mostram que analistas passaram ao ato, 
confundindo precisamente aquilo que tento ressaltar nestas linhas: a distinção entre amor e amor de transferência. Essas passagens ao ato conduzem a catástrofes psíquicas nos analisandos que não precisavam disso, e as conseqüencias às vezes impedem qualquer possibilidade de cura posterior.

\section{PARA TERMINAR COM O AMOR...}

A clínica do enamoramento deve ser, do meu ponto de vista, revisitada em suas singularidades e em suas errâncias. De fato, o sujeito está numa busca, numa demanda de amor que nada nem ninguém poderá preencher.

A complementaridade no outro, ilusão suprema, encontra um impossível estrutural que Lacan designou como aforismo: "Não há relação sexual". Fonte de numerosas interpretações e comentários, esta frase ressalta simplesmente que não pode haver "outro do amor" que venha preencher o desejo e trazer plena satisfação.

Todo sujeito estará assim confrontado de modo irremediável ao impossível da complementaridade no outro. Essa passagem estrutural será encontrada no percurso da análise e só poderá encontrar sua eventual e singular resolução na transferência e em sua possível liquidação.

\section{REFERÊNCIAS BIBLIOGRÁFICAS}

Freud, S. (1921). Psicologia das massas e análise do eu. In Ensaios de psicanálise. Pequena biblioteca, Paris: Payot, 1983.

Freud, S. (1977). Contribuiçōes à psicologia da vida amorosa. In $A$ vida sexual. Paris: PUF.

(1977a). Observações sobre o amor de transferência. In A técnica analítica. Paris: PUF.

Freud, S. (1982). Três ensaios sobre a teoria da sexualidade. Pequena biblioteca, Paris: Payot. 